\title{
Conservation biological control of spirea aphid, Aphis spiraecola (Hemiptera: Aphididae) on apple by providing natural alternative food resources
}

\author{
Mark W. BROWN ${ }^{1}$ and ClarisSa R. MATHEWS ${ }^{2}$ \\ ${ }^{1}$ U.S. Dept. Agriculture, Appalachian Fruit Research Station, 2217 Wiltshire Road, Kearneysville, WV 25430, USA; \\ e-mail: mark.brown@ars.usda.gov \\ ${ }^{2}$ Shepherd University, Institute for Environmental Studies, 35 Snyder Hall, Shepherdstown, WV 25443, USA
}

Key words. Interplanting, extrafloral nectar, habitat management, Harmonia axyridis, Malus domestica, Aphis spiraecola

\begin{abstract}
Enhancing biological control in orchards is an efficient way to control insect pests. This study investigates the possibility of increasing biological control of spirea aphid by providing alternate food resources, in the form of peach extrafloral nectar, to adult Harmonia axyridis, its primary predator. Two pairs of apple orchards, each having one interplanted with $50 \%$ trees bearing extrafloral nectar and one a monoculture, were studied for aphid and predator populations from 1999 to 2005 . There were no differences in spirea aphid or predator populations between interplanted and monoculture orchards. However, $H$. axyridis adults arrived earlier in the interplanted than in the monoculture orchards. In another apple orchard, the effect of peach extrafloral nectar on sentinel spirea aphid colonies surrounding a cluster of potted peach trees, or a cluster of apple trees as a control, was tested in 2007. Only the closest spirea colonies to the potted peach trees, trees within $3 \mathrm{~m}$, showed an increase in biological control. Although there was some indication of enhancement of predation by adult $H$. axyridis on spirea aphids, adding alternative food resources in the form of peach trees bearing extrafloral nectar resulted in no detectable increase in biological control.
\end{abstract}

\section{INTRODUCTION}

Habitat management to increase conservation biological control has become a significant area of research (Landis et al., 2000) and has been proposed as a method to increase sustainability through enhanced biodiversity (Boller et al., 2004). In apple, Malus domestica (Borkh.), orchards several researchers have demonstrated the potential for companion plants to increase biological control (Bugg \& Waddington, 1994; Jenser et al., 1997; Stephens et al., 1998; Brown \& Glenn 1999; Bostanian et al., 2004). Enhancement of aphid biological control on apple has been accomplished with companion plants (Wyss, 1995; Brown et al., 1997) but other research has found no effect of companion plants on aphid populations (Gruys, 1982; Haley \& Hogue, 1990; Brown \& Glenn, 1999). Interplanting species of fruit trees bearing extrafloral nectaries into apple orchards has also been suggested (Brown $\&$ Mathews, 2005). The incorporation of extrafloral nectar sources for manipulating biological control has gained considerable interest in a number of systems (Wäckers et al., 2005).

Spirea aphid, Aphis spiraecola Patch, has become the most abundant aphid on apple in eastern North America (Brown et al., 1995). These aphids feed on young foliage and generally do not damage fruit, however, in high populations they can feed directly on fruit (Oatman \& Legner, 1961) and reduce apple tree vigor (Hamilton et al, 1986; Kaakeh et al., 1992). Adult Harmonia axyridis Pallas (Coleoptera: Coccinellidae) are the most effective predators of spirea aphid in West Virginia USA (Brown, 2004) since it first arrived in eastern North American apple orchards in 1994 (Brown \& Miller, 1998). The effectiveness of adult $H$. axyridis is a result of its arrival early during the aphid colonization phase on apple, mobility and voraciousness (Brown, 2004). Parasitoids of spirea aphid on apple in eastern North America are rare (Brown, 2004). The present study was conducted to assess the possibility of increasing biological control of spirea aphid on apple by interplanting peach (Prunus persica Batsch) trees bearing extrafloral nectaries.

\section{MATERIALS AND METHODS}

\section{Interplanting experiment}

Experiments were conducted in research orchards that were not treated with insecticides, located at the Appalachian Fruit Research Station in Kearneysville WV, USA, from 1999 to 2005. The orchards were managed the same, and received standard horticultural treatments other than insecticides; including mowing, weed control, pruning, and fungicides for disease management. Spirea aphid abundance was studied in 4 orchards, 2 were apple monocultures paired with adjacent apple orchards interplanted with peach. The interplanted orchards had $50 \%$ of the trees as peach ("Loring") having extrafloral nectaries, and 50\% apple ("Granny Smith" and "Royal Empire"). The paired monoculture for these interplanted orchards only had a mixture of the two apple species. These 4 orchards were planted in April 1997 and each was 0.5 ha in size. A commercially managed orchard with standard insecticide applications, also at the Research Station, with "Golden Delicious" planted in 1998 was also monitored for spirea aphid abundance as a chemical predator exclusion control. All orchards were within a $0.5 \mathrm{~km}$ radius and the paired monoculture and interplanted orchards were separated by a $10 \mathrm{~m}$ buffer strip.

The numbers of leaves infested with spirea aphid on 10 branches from 10 randomly selected trees were sampled from early May when aphids were first observed until the aphid infestation ended, usually by late June. Data were analyzed with a 
paired t-test to test for differences between populations in the interplanted and monoculture orchards $(\mathrm{P}=0.05)$ using year as replication. A sign test was used to compare the date of first arrival between orchard pairs for adult $H$. axyridis $(\mathrm{P}=0.10$, the higher probability level was chosen due to the lower power of the test and fewer degrees of freedom) using year as replication.

\section{Manipulation experiment}

A 0.5 ha apple orchard ("Gala" and "Fuji") planted in December 2001, also located at the Research Station, was used to examine the distance at which peach extrafloral nectar affects biological control of spirea aphid. In the middle of one half of the orchard a cluster of 7 potted "Loring" peach trees were placed, the other half of the orchard had a cluster of 7 potted "Gala" apple trees in 2007. The number of potted trees was selected to mimic the relative area of tree foliage found on the surrounding orchard trees. Four sample trees were selected at each of 4 increasingly large concentric ovals from the potted trees. The first oval was made up of the immediately adjacent trees ranging 2.7 to $3.1 \mathrm{~m}$ from the potted trees. The second oval ranged 9.5 to $11.7 \mathrm{~m}$, the third oval 13.4 to $20.0 \mathrm{~m}$ and the fourth oval 29.0 to $30.9 \mathrm{~m}$ from the potted trees. Ovals rather than circles were used due to tree spacing limitations within the orchard, trees within a row ranged from $2.4 \mathrm{~m}$ to $3.6 \mathrm{~m}$ and between row spacing was a consistent $4.8 \mathrm{~m}$.

On each sample tree one leaf infested with greenhouse reared spirea aphids was placed on each of two branch tips and caged for 2 to 3 days. Once the sentinel colonies were established the cages were removed and number of aphids per colony counted. Counts were made daily for a week on all colonies recording the number of aphids per colony. For each replicate there were a total of 8 colonies in each oval for a total of 32 colonies surrounding the potted peach, another 32 colonies surrounded the potted apple trees. There were 4 replicates initiated on 15, 30 May and 12, 26 June; in two replicates the potted peach trees were in the north half of the orchard and in the other two replicates the potted apple trees were in the north half. No insecticides were used in this orchard during the course of the experiment. Data were analyzed using the Friedman rank test comparing the change in aphid population among the 8 treatments: 4 concentric ovals around the peach and 4 around the apple trees.

\section{RESULTS}

There were no consistent differences in population density of spirea aphids between interplanted and monoculture orchards. Abundance of spirea aphid in 2002, the year in which the largest number of observations was made, is presented in Fig. 1. Spirea aphid populations in all 4 of the sampled orchards were very similar in 2002, and in all other sample years, with no one orchard or treatment being consistently different (paired t-test, $\mathrm{P}>$ $0.05)$. In the commercially managed orchard that was monitored, populations were consistently high, attaining an average of more than 6 infested leaves per branch each year.

It was noticed that $H$. axyridis adults, the most abundant predator observed, appeared in the interplanted orchard earlier than the monoculture orchard. Of the 12 paired data, 6 years with 2 orchard pairs (interplanted and monoculture) per year, adult $H$. axyridis were observed first in the interplanted orchards 6 times and first in the monoculture once. In the 5 other data pairs $H$. axyridis adults were observed to arrive at the same sample period in both orchards. This difference in first observation times

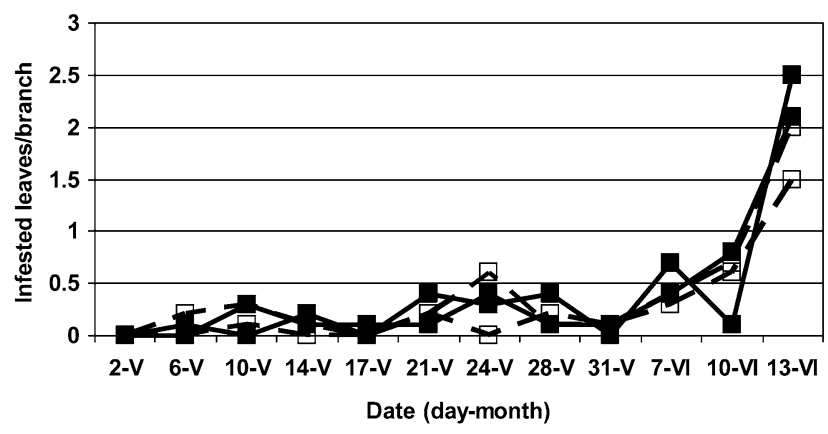

Fig. 1. Spirea aphid population densities for 2 reps of interplanted orchards (solid lines and solid squares) and 2 reps of monoculture orchards (dashed lines and open squares) for 2002.

was significant (sign test, d.f. $=7, \mathrm{P}=0.0625$ ). The average date of the first arrival of adult $H$. axyridis in the interplanted orchard was 11 May and in the monoculture orchard 18 May.

There was a significant treatment effect in the concentric oval manipulation experiment (Chi Square $=15.83$, d.f. $=7, \mathrm{P}<0.05)$. The inner oval comprised of colonies on trees adjacent to the potted peach trees had a significantly greater reduction in population than any other treatment (Fig. 2). There were no other treatment differences among the other concentric ovals around the potted peach trees or around the apple trees (Fig. 3), tested with a Friedman test excluding the inner oval around the peach trees $($ Chi Square $=4.46$, d.f. $=6, \mathrm{P}>0.25)$. The only predator that was abundant during this experiment was adult $H$. axyridis.

\section{DISCUSSION}

There were significant differences in some parameters of biological control as a result of the presence of peaches bearing extrafloral nectar. Harmonia axyridis adults were observed on apple branches earlier in the interplanted orchard than in monoculture orchards. The food provided by the peach extrafloral nectar may have kept these ladybirds in the orchard so that when spirea aphids migrated into the orchard $H$. axyridis adults were present and did

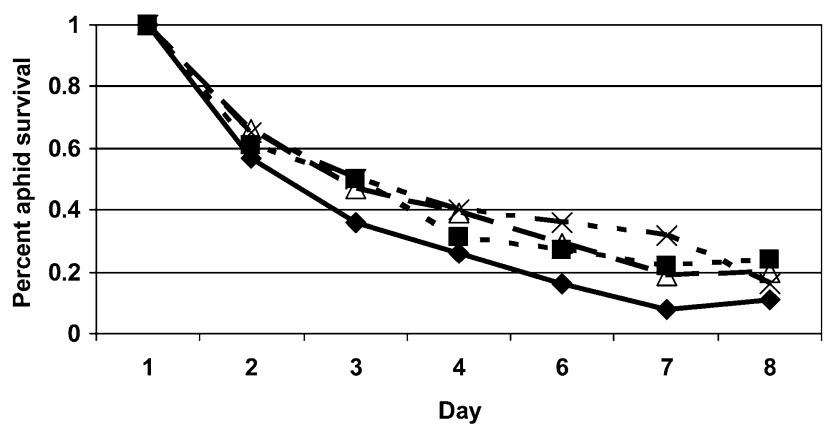

Fig. 2. Percent survival of spirea aphids sentinel colonies in concentric ovals around potted peach trees, day 1 is the day cage was removed and first count of aphids was made: first oval (nearest potted peaches), solid line and solid diamonds; second oval, short dashed line and solid squares; third oval, long dashed line and open triangles; fourth oval, long and short dashed line and " $\mathrm{X}$ ". 




Fig. 3. Percent survival of spirea aphids sentinel colonies in concentric ovals around potted apple trees, day 1 is the day cage was removed and first count of aphids was made: first oval (nearest potted apples), solid line and solid diamonds; second oval, short dashed line and solid squares; third oval, long dashed line and open triangles; fourth oval, long and short dashed line and " $\mathrm{X}$ ".

not need to respond from more distant habitats. Biological control of spirea aphid on trees immediately adjacent to potted peach trees, within $3 \mathrm{~m}$ of the nectar source, was significantly greater than for spirea aphids on trees more distant from the nectar source or on trees at any distance from potted apple trees, which provided no additional food resources (Figs 2, 3).

However, there was no effect of the presence of extrafloral nectar on biological control in the larger orchard experiment. Harmonia axyridis adults are such good predators of spirea aphid on apple that they are capable of providing adequate control without habitat enhancement (Brown \& Miller, 1998). In this study, even the highest population of spirea aphid in the interplanted or monoculture orchards was below the action threshold of 4 infested leaves per branch (Hogmire, 1995). The commercially managed orchard that kept $H$. axyridis and other predators from being effective exceeded the action threshold for spirea aphid control several times per year. Since the arrival of $H$. axyridis, adult ladybirds have been able to provide adequate control of spirea aphid when not interfered with by the use of insecticides (Brown \& Miller, 1998; Brown 2004).

There may be another factor contributing to the lack of effectiveness of interplanting nectar-providing peach trees for enhancing aphid biological control in apple orchards. A laboratory study showed that over a period of 4 hours, there was less biological control of spirea aphid in the presence of peach shoots bearing extrafloral nectar than in the presence of no additional food sources or in the presence of buckwheat flowers (Fagopyrum esculentum) (Spellman et al., 2006). We also found that interplanting $50 \%$ of an apple orchard with extrafloral nectar-providing fruit trees reduced the amount of biological control of rosy apple aphid (Dysaphis plantaginea) by adult $H$. axyridis in a field test (Brown \& Mathews, 2007). An abundance of alternate food sources for $H$. axyridis can, therefore, result in less biological control through interference of host finding or satiation on non-aphid food.

Although adult $H$. axyridis is a very effective predator of spirea aphid on apple, there was some evidence of enhancement of biological control by the providing of alternate food resources in the form of peach extrafloral nectar. The inability to demonstrate an increase in actual biological control of spirea aphid may be due to the high mobility and voracity of adult $H$. axyridis or interference from too many alternate sources of food. Another contributing factor is that biological control is an ecosystem service provided by the ecosystem as a whole (Boller et al., 2004). The difficulty in analyzing the effects of ecosystem services is that the service is provided by all the interactions of the ecosystem as a whole. By separating the various components contributing to the service, the overall interaction can be affected by more than the effects of the single component being tested. Manipulation of ecosystems to enhance biological control, or other ecosystem services, needs to be investigated in a more holistic method, studying the effects of entire systems rather than each component independently.

ACKNOWLEDGMENTS. We thank B. Short for his management of the field plots and data collection. This project was supported in part by the National Research Initiative of the USDA Cooperative State Research, Education and Extension Service, grant no. 2003-35316-13773.

\section{REFERENCES}

Boller E.F., Häni F. \& Poehling H.-M. (ed.) 2004: Ecological Infrastructures: Ideabook on Functional Biodiversity at the Farm Level. IOBC/WPRS, Mattenbach AB, Winterthur, Switz, xiv +212 pp.

Bostanian N.J., Goulet H., O’Hara J., Masner L. \& Racette G. 2004: Towards insecticide free apple orchards: flowering plants to attract beneficial arthropods. Biocont. Sci. Tech. 14: 25-37.

BRown M.W. 2004: Role of aphid predator guild in controlling spirea aphid populations on apple in West Virginia, USA. Biol. Control 29: 189-198.

Brown M.W. \& GLENN D.M. 1999: Use of ground cover plants as a pest management tool in apple orchards. J. Econ. Entomol. 92: 899-905.

Brown M.W. \& Mathews C.R. 2005: Components of an ecologically and economically sustainable orchard. IOBC/WPRS Bull. 28(7): 73-76.

Brown M.W. \& Mathews C.R. 2007: Conservation biological control of rosy apple aphid, Dysaphis plantaginea (Passerini), in eastern North America. Environ. Entomol. 36: 1131-1139.

Brown M.W. \& Miller S.S. 1998: Coccinellidae (Coleoptera) in apple orchards of eastern West Virginia and the impact of invasion by Harmonia axyridis. Entomol. News 102: 136-142.

Brown M.W., Hogmire H.W. \& Schmitt J.J. 1995: Competitive displacement of apple aphid by spirea aphid (Homoptera: Aphididae) on apple as mediated by human activities. Environ. Entomol. 24: 1581-1591.

Brown M.W., Vander Zwet T. \& Glenn D.M. 1997: Impact of ground cover plants on pest management in West Virginia, USA, apple orchards. Hort. Sci. (Prague) 24: 39-44.

BugG R.L. \& WAdDINGTon C. 1994: Using cover crops to manage arthropod pests of orchards: A review. Agric. Ecosyst. Environ. 50: 11-28.

Gruys P. 1982: Hits and misses. The ecological approach to pest control in orchards. Entomol. Exp. Appl. 31: 70-87.

Haley S. \& Hogue E.J. 1990: Ground cover influence on apple aphid, Aphis pomi DeGeer (Homoptera: Aphididae), and its predators in a young apple orchard. Crop Prot. 9: 225-230. 
Hamilton G.C., Swift F.C. \& Marini R. 1986: Effect of Aphis pomi (Homoptera: Aphididae) density on apples. J. Econ. Entomol. 79: 471-478.

Hogmire H.W. (ed.) 1995: Mid-Atlantic Orchard Monitoring Guide. NRAES-75, Northeast Regional Agric. Engineering Service, Ithaca, $361 \mathrm{pp}$.

Jenser G., Balász K., Erdélyi C., Haltrich A., KozÁr F., Markó V., Rácz V. \& SAmu F. 1997: The effect of an integrated pest management program on the arthropod populations in a Hungarian apple orchard. Hort. Sci. (Prague) 24: 63-76.

KaAkeh W., Pfeiffer D.G. \& Marini R.P. 1992: Combined effects of spirea aphid (Homoptera: Aphididae) and nitrogen fertilization on net photosynthesis, total chlorophyll content, and greenness of apple leaves. J. Econ. Entomol. 85: 939-946.

Landis D.A., Wratten S.D. \& GurR G.M. 2000: Habitat management to conserve natural enemies of arthropod pests in agriculture. Annu. Rev. Entomol. 45: 175-201.
OAtman E.R. \& Legner E.F. 1961: Bionomics of the apple aphid Aphis pomi, on young nonbearing apple trees. J. Econ. Entomol. 54: 1034-1037.

Spellman B., Brown M.W. \& Mathews C.R. 2006: Effect of floral and extrafloral resources on predation of Aphis spiraecola by Harmonia axyridis on apple. BioControl 51: 715-724. Stephens M.R., France C.M., Wratten S.D. \& Frampton C. 1998: Enhancing biological control of leafrollers (Lepidoptera: Tortricidae) by sowing buckwheat (Fagopyrum esculenteum) in an orchard. Biocont. Sci. Tech. 8: 547-558.

Wäckers F.L., RiJn P.C.J. \& BRuIN J. (eds) 2005: Plantprovided Food for Carnivorous Insects: A Protective Mutualism and its Applications. Cambridge Univ. Press. Cambridge, $368 \mathrm{pp}$.

Wyss E. 1995: The effects of weed strips on aphids and aphidophagous predators in an apple orchard. Entomol. Exp. Appl. 75: 43-49.

Received September 18, 2007; revised and accepted December 12, 2007 